\title{
Quantum yields of photocoloration and molar absorption coefficients of ferrocenyl substituted benzo and dibenzochromenes. Comparison with their phenyl-homologues
}

\author{
Pierre Brun, ${ }^{1, \dagger}$ Robert Guglielmetti, ${ }^{1}$ Jean Claude Micheau, ${ }^{2, \neq}$ \\ Véronique Pimienta, ${ }^{2}$ and Stéphane Anguille ${ }^{1}$ \\ ${ }^{1}$ UMR 6114, Université de la Méditerranée, 163 Avenue de Luminy, 13288, Marseille cedex 9, France \\ ${ }^{2}$ UMR 5623, Université Paul Sabatier, 118 Route de Narbonne, 31062, Toulouse cedex, France
}

\begin{abstract}
The photochromic properties of three ferrocenyl-[2H]-benzopyrans were investigated under monochromatic irradiation and compared with those of their phenyl homologues. The UV/visible spectra of the closed and open forms are reported together with the quantum yields of photocoloration. It was shown that the ferrocenyl- substitution induces the formation of a new band in the 500-700 nm range in the open forms, however, it does not affect significantly the UV spectra of the closed forms. Ferrocenyl- substitution was also shown to increase the thermal bleaching rate constants and to decrease the photocoloration quantum yields. For most compounds, photochromic behaviour was not sensitive to the irradiation wavelength. However, for the methyl ferrocenyl chromene, the open form spectrum was slightly dependent of the irradiation wavelength. The influence of the ferrocenyl group and other structural features on the photochromic properties are discussed.
\end{abstract}

\section{INTRODUCTION}

[2H]-benzopyrans (elsewhere called $2 \mathrm{H}$-chromenes) are photochromic compounds. They undergo a photocleavage of the $\mathrm{C}-\mathrm{O}$ bond leading to a photomerocyanine form often referred as the open form (OF) (Scheme 1) [1]. Due to electronic delocalization, the absorption range of the open form is shifted towards longer wavelengths, i.e. from the UV to the visible region. The thermally reversible closure of the photomerocyanine gives the starting $[2 \mathrm{H}]$-benzopyran which is often referred as the closed form (CF).

Their photochromic behaviour is characterized by the UV spectra of the closed and open forms $\left(\varepsilon_{\mathrm{CF}}{ }^{\lambda}\right.$ and $\left.\varepsilon_{\mathrm{OF}}^{\lambda}\right)$, by the thermal bleaching kinetic rate constants $\left(\mathrm{k}_{\triangle}\right)$ and by the value of the quantum yield of the reversible photocoloration $\left(\phi_{\mathrm{col}}\right)$. These photochromic parameters are greatly influenced by the nature of the $\mathrm{R}^{1}$ and $\mathrm{R}^{2}$ groups placed on the Csp3 in the 2-position [2] and by the size of the aromatic moiety (benzo[ $h]$ or dibenzo[ $f, h]$ chromene). Moreover, the replacement of a phenyl group by a ferrocenyl one at the 2-position [3] leads to open forms with two $\lambda_{\max }$ resulting in a strong absorption range extension in the visible region [4]. The back closure process is accelerated and some stabilized photomerocyanines are observed in alcohol solutions [5]. It was also shown that the resistance to the

\footnotetext{
† E-mail: brun@luminy.univ-mrs.fr

‡ E-mail: micheau@chimie.ups-tlse.fr
}

photodegradation was increased. Three ferrocenylbenzopyrans [3, 4] (1a-3a) and their phenylhomologues [6] (1b-3b) (Scheme 2) were studied under monochromatic irradiation (313 and $366 \mathrm{~nm}$ ) in order to determine their photocoloration quantum yields and the molar absorption coefficients of their transient open forms.

\section{RESULTS AND DISCUSSION}

2.1. UV spectra of the closed forms. Spectral analysis of the closed form $\left[\lambda(\mathrm{nm}), \varepsilon\left(\mathrm{L} \cdot \mathrm{mol}^{-1} \cdot \mathrm{cm}^{-1}\right)\right]$ has been realized in toluene and the results are reported in Table 1 (see Figure 1 for the detailed UV spectra of $\mathbf{2 a}$ and $2 \mathbf{b})$.

Table 1 shows that for each compound, there are several well-defined bands or shoulders that appear in the same narrow spectral range $\left(1^{\text {st }} \lambda_{\max }\right.$ : $315-$ $317,2^{\text {nd }} \lambda_{\text {max }}: 326-333,3^{\text {rd }} \lambda_{\max }: 340-345,4^{\text {th }} \lambda_{\max }$ : $\left.354-356,5^{\text {th }} \lambda_{\max }: 374-375 \mathrm{~nm}\right)$. Spectra of the ferrocenyl substituted compounds $\mathbf{1 a}, \mathbf{2 a}$, 3a are not significantly different from those of their phenyl homologues $\mathbf{1 b}, \mathbf{2 b}$ and $\mathbf{3 b}$. On the other hand, phenanthrenocompounds $\mathbf{3 a}$ and $\mathbf{3 b}$ exhibit a characteristic strong band at 374-375 nm which appear to be specific for the phenanthreno-annellation. These results confirm that the pyranic moiety is responsible for the lower energy absorption bands of the closed form. Figure 1 shows the similarity between UV spectra of the closed forms of ferrocenyl- and phenyl-homologues. 


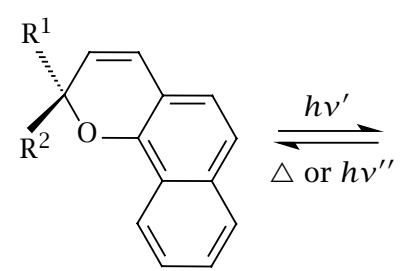

Closed Form (CF)

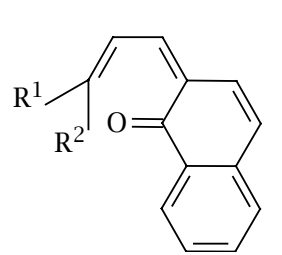

Cisoïd Open Form

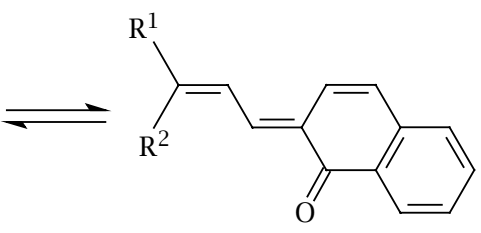

Transoïd Open Form (OF)

Scheme 1. Ring opening and ring closure of benzo-chromenes under irradiation.

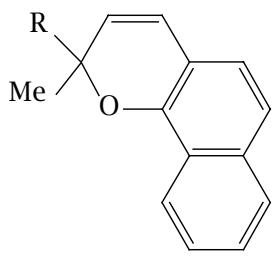

$\mathrm{R}=\mathrm{Fc}: \mathbf{1 a}$

$\mathrm{R}=\mathrm{C}_{6} \mathrm{H}_{5}: \mathbf{1 b}$

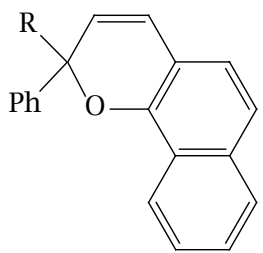

$\mathrm{R}=\mathrm{FC}: \mathbf{2 a}$

$\mathrm{R}=\mathrm{C}_{6} \mathrm{H}_{5}: \mathbf{2} \mathbf{b}$

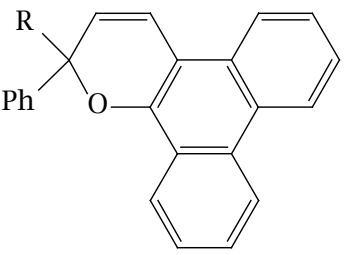

$\mathrm{R}=\mathrm{Fc}: \mathbf{3 a}$

$\mathrm{R}=\mathrm{C}_{6} \mathrm{H}_{5}: 3 \mathbf{b}$

Scheme 2. Structures of the studied compounds $(F \mathrm{C}=$ ferrocenyl).

Table 1. UV spectra of compounds $\mathbf{1 a}-\mathbf{3 b}$.

\begin{tabular}{lccccc}
\hline no. & $1^{\text {st }} \lambda_{\max }, \varepsilon_{\max }$ & $2^{\text {nd }} \lambda_{\max }, \varepsilon_{\max }$ & $3^{\text {rd }} \lambda_{\max }, \varepsilon_{\max }$ & $4^{\text {th }} \lambda_{\max }, \varepsilon_{\max }$ & $5^{\text {th }} \lambda_{\max }, \varepsilon_{\max }$ \\
\hline $\mathbf{1 a}\left(^{*}\right)$ & 317,4250 & 327,4800 & 340,5000 & 354,4270 & $(-)$ \\
1b & $317(\mathrm{~s}), 4000$ & 326,4600 & 340,4950 & 355,4380 & $(-)$ \\
2a & $(-)$ & 328,4360 & 340,4500 & 354,4100 & $(-)$ \\
2b & 315,4000 & 327,4500 & 341,4700 & 356,4100 & $(-)$ \\
3a & $(-)$ & $(-)$ & 344,5950 & $354(\mathrm{~s}), 5560$ & 375,4090 \\
3b & $(-)$ & $333(\mathrm{~s}), 4200$ & 345,4730 & $355(\mathrm{~s}), 4400$ & 374,3080 \\
\hline
\end{tabular}

*: solvent: ma = methanol-acetonitrile $90-10 \mathrm{v} / \mathrm{v}$; (s): shoulder, (-): no maximum.

2.2. Effect of the irradiation wavelength on $U V$ visible spectra of the open forms of compound $1 \mathrm{a}$ in methanol. The photochromism of these compounds has been investigated in four solvents: acetonitrile (a), ethanol (e) or methanol (m) and toluene (t) using independently two monochromatic irradiation wavelengths (313 and $366 \mathrm{~nm}$ ). Usually, they lead to the same distribution of open forms with the same UV/visible spectra. However, in the case of 1a in methanol, an unexpected effect has been observed. Both irradiation wavelengths lead to the formation of a broad spectrum exhibiting three bands at 387, 470 and $609 \mathrm{~nm}$. But, when the irradiation is performed at $366 \mathrm{~nm}$, the absorbances at 470 and $609 \mathrm{~nm}$ are smaller and the $387 \mathrm{~nm}$ band remains stable (i.e., there is no bleaching in the dark for this specific band) (Figure 2).

Such behaviour was already observed under polychromatic irradiation. A possible explanation would be the presence of a wavelength and irradiation time dependent proportion of the various expected photoisomers CCC, CTT, CTC, TTC and TTT (Figure 3). They are able to undergo, either thermally or photochemically induced interconversions. If the thermal interconversion is slow, the photochemical interconversion prevails. Then, depending of their relative molar absorption coefficients at the UV irradiation wavelength, different distributions are likely to be established. The more energetic $313 \mathrm{~nm}$ irradiation could induce the partial photo-destruction of the long-lived photoisomer monitored at $387 \mathrm{~nm}$ letting it to accumulate under $366 \mathrm{~nm}$ irradiation.

2.3. Kinetic study of the thermal decay. Under continuous monochromatic irradiation, a rather large proportion (from 42 to 95\%) of the open forms was reached at steady state. As it has been shown with compound 1a in methanol, depending on the nature of the irradiated compound, the irradiation wavelength, the photon flux, the solvent and the duration of the irradiation, several isomers are likely to be present. After the irradiation has been shut down, the system undergoes a thermal bleaching, however this process is not $100 \%$ 


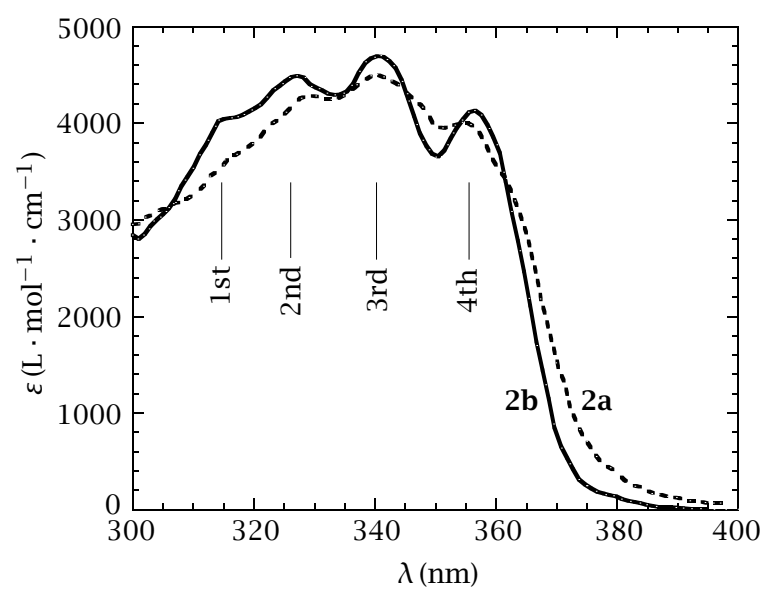

Figure 1. Spectra of typical closed forms in toluene (compounds $2 \boldsymbol{a}$ (ferrocenyl-) and phenyl-homologue $2 \boldsymbol{b}$ ). Note the presence on the two homologue compounds of the similar intensity and wavelength range for the four spectral bands.

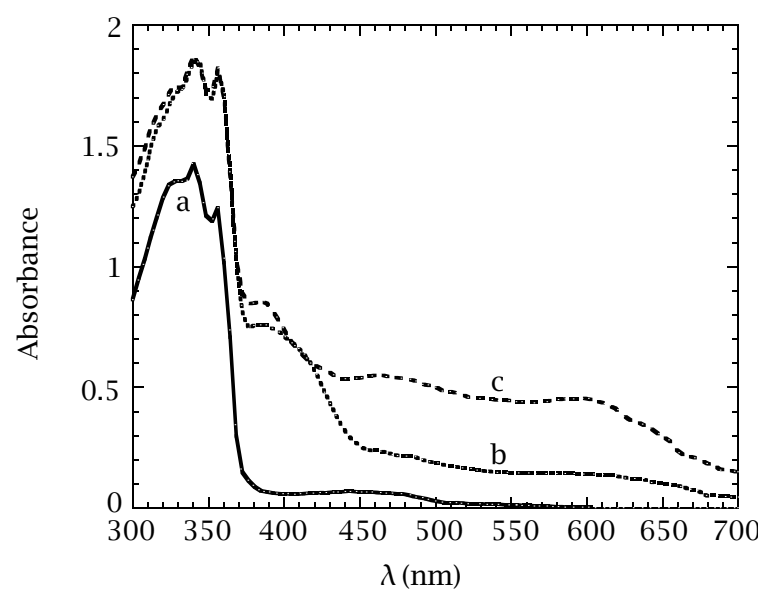

Figure 2. Comparison of the UV/visible spectra obtained after irradiation at 313 or $366 \mathrm{~nm}$ of a $3 \times 10^{-4} \mathrm{~mol} \cdot \mathrm{L}^{-1}$ methanolic solution of 1a. Spectra: a: initial; $b$ : after irradiation at $366 \mathrm{~nm}$; : after irradiation at $313 \mathrm{~nm}$.

reversible, a certain amount of the coloured species (hereby specified as long-lived species) remains relatively stable within the time-scale of observation and do not participate to the mono-exponential decay that has been recorded for all the compounds. Results are gathered in Table 2.

Within the time-scale of our kinetic technique (i.e., $0.1 \mathrm{~s}$ to $10000 \mathrm{~s}$ ), a large amplitude thermal decay has been recorded for all compounds under investigation. These kinetics were characterised by a first-order rate constant $\mathrm{k}_{\triangle}$. Lower $\mathrm{k}_{\triangle}$ values are for compounds $\mathbf{2 a}$ and $\mathbf{2 b}$ in toluene, while higher $\mathrm{k}_{\triangle}$ is in the more polar solvent acetonitrile (1b). Our measurements show also<smiles>[R]C(F)=CC=C1C=Cc2ccccc2C1=O</smiles><smiles>[R]C(F)=CC=C1C=Cc2ccccc2C1=O</smiles><smiles>[R]C(F)=CC=C1C=Cc2ccccc2C1=O</smiles>

Figure 3. Main stereoisomers of the open form.

that the replacement of the phenyl group by a ferrocene increases the thermal bleaching: $\mathrm{k}_{\triangle}(2 \mathrm{a})>\mathrm{k}_{\triangle}(2 \mathrm{~b})$ and $\mathrm{k}_{\triangle}(3 \mathbf{a})>\mathrm{k}_{\triangle}(\mathbf{3 b})$. The same effect is observed when a methyl group replaces a phenyl one: $\mathrm{k}_{\triangle}(\mathbf{1 b})>\mathrm{k}_{\triangle}(\mathbf{2 b})$ and when a phenanthrene nucleus replaces a naphthalene one: $\mathrm{k}_{\triangle}(3 \mathbf{b})>\mathrm{k}_{\triangle}(2 \mathbf{b})$ and $\mathrm{k}_{\triangle}(3 \mathbf{a})>\mathrm{k}_{\triangle}(\mathbf{2 a})$.

There is a slight irradiation wavelength effect on the percentage of stable long-lived species formed after irradiation. The origin of this effect is likely to be the same than for compound 1a in methanol solution (i.e., a variable distribution of several possible photoisomers). However, after standing for a long time in the dark (several hours or days), a slow thermal bleaching occurs [7]. This spontaneous long-time decay was never complete, ferrocenyl compounds $\mathbf{1 a}, \mathbf{2 a}$ and $\mathbf{3 a}$ appeared always to contain, in toluene solution and at room temperature $1,4.8$, and $10 \%$ of the open forms, respectively. This long-term stable proportion was less important for the phenyl-homologues, respectively 0.4 , 0.8 and $1 \%$ for $\mathbf{1 b}, \mathbf{2} \mathbf{b}$, and $\mathbf{3 b}$. The presence of such small quantities of stable open form is likely to be related to a thermal equilibrium between the closed and open stereoisomers (i.e., a slight thermochromic effect).

\subsection{Kinetic modelling of the Absorbance vs time} curves under continuous monochromatic irradiation. From kinetic modelling of Absorbance vs time photokinetic curves [8], quantitative UV-visible spectra of the reversible open forms (lifetime $<1000 \mathrm{~s}$ ) and quantum yields of photocoloration can be extracted.

\subsubsection{Quantitative UV/visible spectra of the opened forms}

The molar absorption coefficients of the reversible open forms (OF) that have been obtained after kinetic modelling are gathered on the Table 3 .

Figure 4 presents the calculated spectra of compounds $\mathbf{1 b}, \mathbf{2} \mathbf{a}, \mathbf{2} \mathbf{b}$ and $\mathbf{3 a}$ as they have been obtained from the kinetic modelling. For ferrocenyl-containing compounds $\mathbf{2} \mathbf{a}$ and $\mathbf{3 a}$, the main feature is the presence 
Table 2. \% (after irradiation) of long-lived isomers of the open form and thermal bleaching rate constant $\mathrm{k}_{\triangle}$ for compounds 1-3 (both monitored at $\left.\lambda_{\text {obs }}\right)(\mathrm{T}=298 K)$.

\begin{tabular}{lcccc}
\hline no. & solvent & \% long-lived isomers after irradiation at 313; 366 nm & $\mathrm{k}_{\triangle}\left(10^{-3} \mathrm{~s}^{-1}\right)$ & $\lambda_{\text {obs }}(\mathrm{nm})$ \\
\hline $\mathbf{1 a}$ & $\mathrm{m}$ & $6 ; 8$ & 8.3 & 600 \\
$\mathbf{1 b}$ & $\mathrm{t}$ & $31 ; 26$ & 11.0 & 450 \\
$\mathbf{1 b}$ & $\mathrm{a}$ & $48 ; 51$ & 16.6 & 458 \\
$\mathbf{1 b}$ & $\mathrm{e}$ & $47 ; 34$ & 9.2 & 461 \\
$\mathbf{2 a}$ & $\mathrm{t}$ & $12 ;-$ & 2.4 & 470 \\
$\mathbf{2 b}$ & $\mathrm{t}$ & $23 ; 24$ & 1.45 & 472 \\
3a & $\mathrm{t}$ & $14.4 ; 9.1$ & 9.0 & 447 or 600 \\
3b & $\mathrm{t}$ & $5 ; 12$ & 4.0 & 472 \\
\hline
\end{tabular}

Table 3. Molar absorption coefficients of the transient open forms (OF).

\begin{tabular}{cccccc}
\hline & Solvent & $\lambda_{\text {irr. }}$ & $\varepsilon_{\mathrm{OF}}\left(\mathrm{L} \cdot \mathrm{mol}^{-1} \cdot \mathrm{cm}^{-1}\right)$ & $\left(\lambda_{\max }\right)$ & OF(nm) \\
\hline $\mathbf{1 a}$ & $\mathrm{m} / \mathrm{a}$ & 313 & $11600(358), 12100(386)$, & $5800(466)$, & $4800(600)$ \\
$\mathbf{1 b}$ & $\mathrm{m} / \mathrm{a}$ & 366 & $9900(356), 8800(390)$, & $1600(466)$, & $1000(600)$ \\
$\mathbf{1 b}$ & $\mathrm{a}$ & $313 / 366$ & $10650(330), 11500(460)$ & & \\
$\mathbf{1 b}$ & $\mathrm{t}$ & $313 / 366$ & $9800(336), 11850(454)$ & & \\
$\mathbf{1 b}$ & $\mathrm{e}$ & $313 / 366$ & $10300(336), 11100(460)$ & & $12750(608)$ \\
$\mathbf{2 a}$ & $\mathrm{t}$ & $313 / 366$ & $12600(374), 12250(392)$, & $14350(474)$, & \\
$\mathbf{2 b}$ & $\mathrm{t}$ & $313 / 366$ & $13450(380), 14200(400)$, & $20250(470)$ & \\
3a & $\mathrm{t}$ & $313 / 366$ & $15450(446), 7950(582)$ & & \\
\hline
\end{tabular}

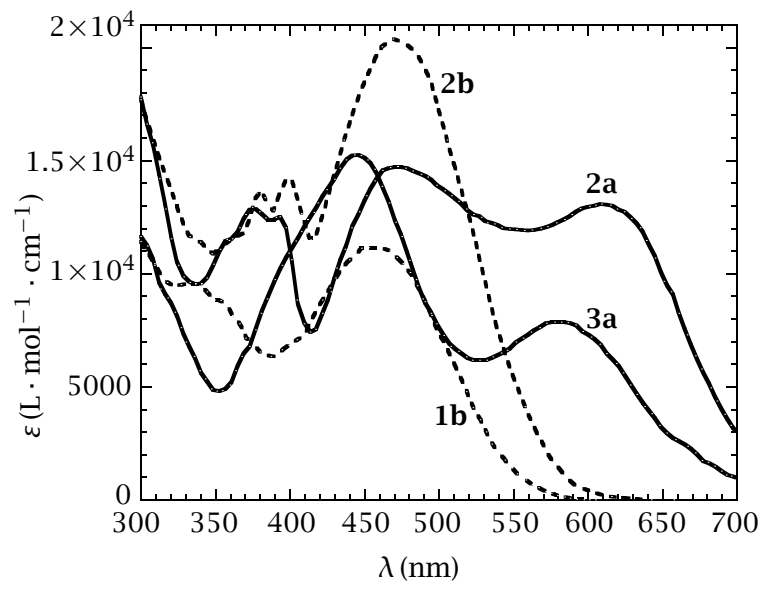

Figure 4. UV-visible spectra of the reversible open forms of compounds $1 \boldsymbol{b}, 2 \boldsymbol{a}, 2 \boldsymbol{b}$ and $3 \boldsymbol{a}$ in toluene solution.

of a specific band within the 580-610 $\mathrm{nm}$ range [5]. For compounds $\mathbf{2 a}$ and $\mathbf{2 b}$, another characteristics is the presence on the lower wavelength part of the spectra of a small "pattern" more or less similar to the UV spectra of the corresponding closed form, but redshifted by $\approx 33 \mathrm{~kJ} \cdot \mathrm{mol}^{-1}$ in $2 \mathrm{a}$ and $\approx 41 \mathrm{~kJ} \cdot \mathrm{mol}^{-1}$ in $\mathbf{2 b}$. It is likely that this pattern would be related to the 12 electrons system of the vinyl-naphthalene moiety encountered either in the closed or open forms. Moreover, as expected, replacement of a methyl by a phenyl increases the conjugation and hence the molar absorption coefficient $\left(\varepsilon_{\mathrm{OF}}(\mathbf{2 b})>\varepsilon_{\mathrm{OF}}(\mathbf{1 b})\right) ; \lambda_{\max }$ is also red-shifted $\left(\lambda_{\max }(\mathbf{2 b})>\lambda_{\max }(\mathbf{1 b})\right)$. This effect is no longer true for ferrocenyl-compounds $\mathbf{2 a}$ and $3 \mathbf{a}$, where phenanthrenyl- (to naphthyl-) substitution induces a blue-shift $\left(\lambda_{\max }(\mathbf{2 a})>\lambda_{\max }(\mathbf{3 a})\right)$ and decreases the molar absorption $\left(\varepsilon_{\mathrm{OF}}(\mathbf{2 a})>\varepsilon_{\mathrm{OF}}(3 \mathbf{a})\right)$.

\subsubsection{Determination of the quantum yields of the reversible photocoloration process}

It was assumed that these quantum yields were not irradiation wavelength sensitive for 313 and $366 \mathrm{~nm}$ (Table 4). This hypothesis was justified because the values that have been extracted independently from the two irradiation wavelength were not significantly different within our experimental accuracy. Values given have been obtained by averaging data from 313 and $366 \mathrm{~nm}$ irradiation. Quantum yield for compound $\mathbf{3 b}$ is not given because it cannot be extracted with a sufficient precision due to lack of convergence in the iterative calculation. Ferrocenyl- compounds $2 \mathbf{a}$ and $3 \mathbf{3}$ exhibit low quantum yields. For compound $2 \mathbf{a}$ and $\mathbf{2 b}$ we have obtained $(\phi(2 \mathbf{b}) \approx 4 \times \phi(\mathbf{2 a}))$. A possible explanation for this weak photoreactivity would be a deactivation of the excited state (either thermally, by fluorescence or by intersystem crossing to a low reactive triplet intermediate) due to the presence of the ferrocene group. Quantum yields are also solvent sensitive, being higher in the less polar solvent. This effect could be interpreted by the presence of a non-reactive short lived state (triplet or transient photoisomer) giving rise to deactivation in the more polar solvent as already described for spiropyrans systems [9]. $\phi_{\text {col }}$ also increases slightly when a phenanthrene nucleus replaces a naph- 
Table 4. Photocoloration quantum yields of various compounds in various solvents.

\begin{tabular}{lccccccc}
\hline $\mathrm{n}^{\mathrm{O}}$ & $\mathbf{1 a}$ & $\mathbf{1 b}$ & $\mathbf{1 b}$ & $\mathbf{1 b}$ & $\mathbf{2 a}$ & $\mathbf{2 b}$ & $\mathbf{3 a}$ \\
\hline solvent & $\mathrm{m} / \mathrm{a}$ & $\mathrm{t}$ & $\mathrm{e}$ & $\mathrm{a}$ & $\mathrm{t}$ & $\mathrm{t}$ & $\mathrm{t}$ \\
\hline$\phi_{\text {coloration }}$ & $0.06 \pm 0.05$ & $0.70 \pm 0.10$ & $0.50 \pm 0.20$ & $0.42 \pm 0.10$ & $0.15 \pm 0.05$ & $0.62 \pm 0.05$ & $0.20 \pm 0.05$ \\
\hline
\end{tabular}

thalene one $\phi_{\text {col }}(3 \mathbf{a})>\phi_{\text {col }}(\mathbf{2 a})$. As the exact molar absorption coefficient of the photoisomers responsible for the non-reversible photocoloration (Figure 2) was not known, the corresponding quantum yields were not determined.

The quantum yield of photocoloration $\phi_{\text {col }}$ and the thermal fading rate constant $\mathrm{k}_{\triangle}$ can be correlated to the experimental photosteady state absorbance (Abspss). Highly colourable compound $2 \mathbf{b}(\operatorname{Abspss}(470) \approx 1.9)$ exhibits a high $\phi_{\text {col }}$ with a low $\mathrm{k}_{\triangle}$. On the other side, weakly colourable compound $3 a$ (Abspss $(582) \approx 0.45$ ) has a low photocoloration quantum yield and a high thermal fading rate constant. In between, lie medium colourable compounds $\mathbf{1 b}$ and $\mathbf{2 a}\left(\operatorname{Abs}_{\mathrm{PSS}}\left(\lambda_{\max }\right) \approx 0.9\right.$ 1.1). The origin of such behaviour can be understood from the photosteady state equation, which shows that Abspss is an increasing function of the ratio $\phi_{\mathrm{col}} / \mathrm{k}_{\triangle}$. The coloration of the solution is proportional to the open form concentration ([OF]) [10]. Then at the photosteady state (PSS), eq. (1) (derived from eq. (3) =0) holds. It shows that $[\mathrm{OF}]_{\mathrm{PSS}}$ is proportional to the ratio $\phi_{\mathrm{col}} / \mathrm{k}_{\triangle}$ :

$$
([\mathrm{OF}] /[\mathrm{CF}])_{\mathrm{PSS}}=\left(\phi_{\mathrm{col}} / \mathrm{k}_{\triangle}\right) \times\left(\varepsilon_{\mathrm{CF}}^{\prime} \mathrm{I}_{0} \mathrm{~F}\right)
$$

\section{CONCLUSION}

Kinetic modelling of Absorbance vs time curves recorded under monochromatic irradiation of a series of ferrocenyl-benzopyrans and their phenyl-homologues has provided interesting results about their quantitative spectral, kinetic and photochromic properties.

It has been shown that the UV spectra of the closed forms was not sensitive to the presence of the ferrocenyl-group at the 2-position. Kinetic measurements have also shown that the rate constant of thermal fading was higher with ferrocenyl compounds than with their phenyl-homologues. However, an unexpected stable open form has been observed with the methyl ferrocenyl-compound 1a in methanol solution. A wavelength and solvent dependent long-lived photoisomer distribution has been assumed.

The molar absorption coefficients of the reversible open forms and the corresponding quantum yields of photocoloration have been determined. The presence of a ferrocenyl-group in the 2-position of the benzopyrans decreases the quantum yield but it leads to a new visible absorption band in the 550-700 nm range. The photocoloration behaviour can be quantitatively correlated to their photochromic parameters.

\section{EXPERIMENTAL PART}

4.1. Chromenes. Their synthesis and characterization has been already published elsewhere $[3,4,6]$.

4.2. Photochromic solutions. The photochromic solutions were obtained by dissolving the corresponding chromenes in spectroscopic grade anhydrous solvents. All the concentrations were in the $3 \times$ $10^{-4} \mathrm{~mol} \cdot \mathrm{L}^{-1}$ range.

4.3. Monochromatic irradiations. The monochromatic irradiation was derived from a filtered $200 \mathrm{~W}$ high pressure mercury lamp using a liquid optical fibre able to deliver around $\approx 130 \mathrm{~W} \cdot \mathrm{m}^{-2}$ in the $300-400 \mathrm{~nm}$ mercury UV lines with a $10 \mathrm{~nm}$ bandwidth. Potassium ferrioxalate was used to determine the photon flux with a precision better than $5 \%$.

at $313 \mathrm{~nm}: \mathrm{I}_{0}=5 \times 10^{-6} \mathrm{~mol} \cdot \mathrm{L}^{-1} \cdot \mathrm{s}^{-1}$, at $366 \mathrm{~nm}: \mathrm{I}_{0}=6 \times 10^{-6} \mathrm{~mol} \cdot \mathrm{L}^{-1} \cdot \mathrm{s}^{-1}$.

The photon flux was checked periodically using a home-made semiconductor light sensor. The photochemical reactor was a $1 \mathrm{~cm} \times 1 \mathrm{~cm}$ thermostated and stirred quartz cell placed in the compartment of a HP8451A diode array spectrophotometer. Several wavelengths including the irradiation one were monitored simultaneously. The data as Abs vs time photokinetic curves were stored and processed using a home-made software.

4.4. Thermal relaxation. Thermal decay occurred after the irradiation photon flux was shut down. Absorbance $v s$ time were recorded during this process. The thermal bleaching constants $\mathrm{k}_{\triangle}$ at $25^{\circ} \mathrm{C}$ were calculated using monoexponential eq. (2) [11-13]

$$
\mathrm{Abs}_{\mathrm{t}}=\mathrm{AbSPSS}_{-}-\left(\mathrm{AbSPSS}_{\mathrm{P}}-\mathrm{Abs}_{\mathrm{o}}\right) \mathrm{e}^{-\mathrm{k} \triangle \mathrm{T}}
$$

In this equation $\mathrm{Abs}_{\mathrm{t}}$ is the absorbance measured at a time $\mathrm{t}, \mathrm{Abs}_{\mathrm{o}}$ is the absorbance measured at time 0 and Abspss is the absorbance at the photo-steady state. Short irradiation times (less than 300 s) were selected in order to minimise photodegradation and long-lived species formation.

4.5. Photocoloration quantum yields and molar absorption coefficients of the transient OF. In order to extract the photochromic parameters ( $\phi_{\text {col }}$ and $\varepsilon_{\mathrm{OF}}$ ), experimental photokinetic curves (Abs $v s \mathrm{t}$ ) were fitted using a kinetic modelling procedure. The model was derived from the simplest photochromic mechanism: $\mathrm{CF} \rightarrow \mathrm{OF}(h v)$; $\mathrm{OF} \rightarrow \mathrm{CF}(\triangle)$ which gives rise to 
the differential and phenomenological equations:

$$
\begin{gathered}
-\mathrm{d}[\mathrm{CF}] / \mathrm{dt}=\phi_{\mathrm{Col}} \mathrm{I}_{0} \varepsilon_{\mathrm{CF}}^{\prime} \mathrm{F}[\mathrm{CF}]-\mathrm{k}_{\triangle}[\mathrm{OF}] \\
\mathrm{Abs}=\varepsilon_{\mathrm{CF}}[\mathrm{CF}]+\varepsilon_{\mathrm{OF}}\left([\mathrm{C}]_{0}-[\mathrm{CF}]\right) \\
{[\mathrm{CF}]+[\mathrm{OF}]=[\mathrm{C}]_{0}}
\end{gathered}
$$

$\varepsilon_{\mathrm{CF}}^{\prime}$ is taken at the irradiation wavelength, $\mathrm{F}$ is the photokinetic factor $[8,11], \mathrm{F}=\left(1-10^{-\mathrm{Abs}^{\prime}}\right) / \mathrm{Abs}^{\prime}$ and $[\mathrm{C}]_{0}$ is the total concentration of the photochromic compound.

The calculated Abs values were obtained by numerical integration using "guessed" values of the unknown parameters, then they were fitted on the experimental ones using a minimisation algorithm able to adjust the initial "guessed" values of the parameters at their optimum. At the end of the fitting procedure, the estimated values of the parameters were delivered. The uniqueness of the solution was tested by showing that whatever the initial values of the guessed parameters the calculation arrived to the same minimum at convergence.

\section{REFERENCES}

[1] (a) J. C. Crano and R. J. Guglielmetti (Eds.), Organic Photochromic and Thermochromic Compounds, Vols. 1 and 2, Kluwer Academic-Plenum Publishers, New York, 1998-1999.

(b) R. S. Becker and J. Michl, J. Am; Chem. Soc. 88 (1966), 5931.

(c) G. Favaro, A. Romani, and R. S. Becker, Photochem. Photobiol. 72 (2000), 632.

[2] (a) B. Van Gemert, in Organic Photochromic and Thermochromic Compounds, (J. C. Crano and R. J. Guglielmetti, Eds.), Vol. 1, Kluwer AcademicPlenum Publishers, New York, 1998, Chapter 3. (b) A. Kumar, Mol. Cryst. Liq. Cryst. 297 (1997), 139.
[3] S. Anguille, Ph.D. Thesis, Marseille-Luminy, France, 2000.

[4] S. Anguille, P. Brun, R. Guglielmetti, Y. P. Strokach, A. A. Ignatin, V. A. Barachevsky, and M. V. Alfimov, J. Chem. Soc. Perkin Trans. 2 (2001), 639.

[5] P. Brun, R. Guglielmetti, G. Pèpe, and S. Anguille, J. Photochem. Photobiol. A, Chem. (in press).

[6] J. L. Pozzo, Ph.D. Thesis, Marseille-Luminy, France, 1994.

[7] (a) G. Ottavi, G. Favaro, and V. Malatesta, J. Photochem. Photobiol. A, Chem. 115 (1998), 123.

(b) B. Luccioni-Houze, M. Campredon, R. Guglielmetti, and G. Giusti, Mol. Cryst., Liq. Cryst. 297 (1997), 161.

[8] V. Pimienta, D. Lavabre, G. Levy, A. Samat, R. Guglielmetti, and J. C. Micheau, J. Phys. Chem. 100 (1996), 4485.

[9] R. C. Bertelson, Photochromic Processes involving heterocyclic cleavage in: Photochromism (G. H. Brown, Ed.), Wiley-Interscience, New-York, 1971, Chapter 3, pp. 45-431.

[10] N. Rebière, C. Moustrou, M. Meyer, A. Samat, R. Guglielmetti, J. C. Micheau, and J. Aubard, J. Phys. Org. Chem. 13 (2000), 1.

[11] M. H. Deniel, D. Lavabre, and J. C. Micheau, in Organic Photochromic and Thermochromic Compounds, Vol. 2, (J. C. Crano and R. J. Guglielmetti, Eds.), Kluwer Academic-Plenum Publishers, New York, 1999, chapter 3, pp. 167-209.

[12] A. V. Metelitsa, J. C. Micheau, N. A. Voloshin, E. N. Voloshina, and V. I. Minkin, J. Phys. Chem. B. 105 (2001), 8417.

[13] V. Pimienta and J. C. Micheau, Mol. Liq. Liq. Cryst. 344 (2000), 157. 


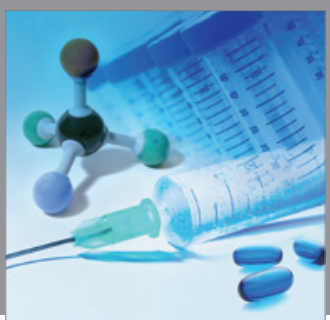

International Journal of

Medicinal Chemistry

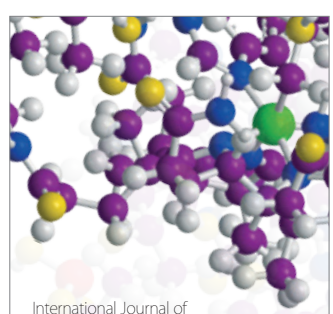

Carbohydrate Chemistry

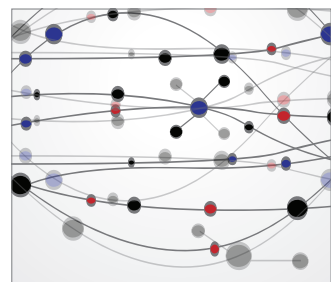

The Scientific World Journal
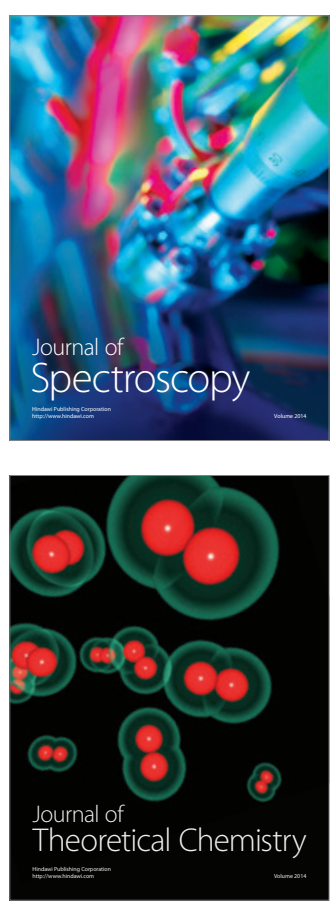
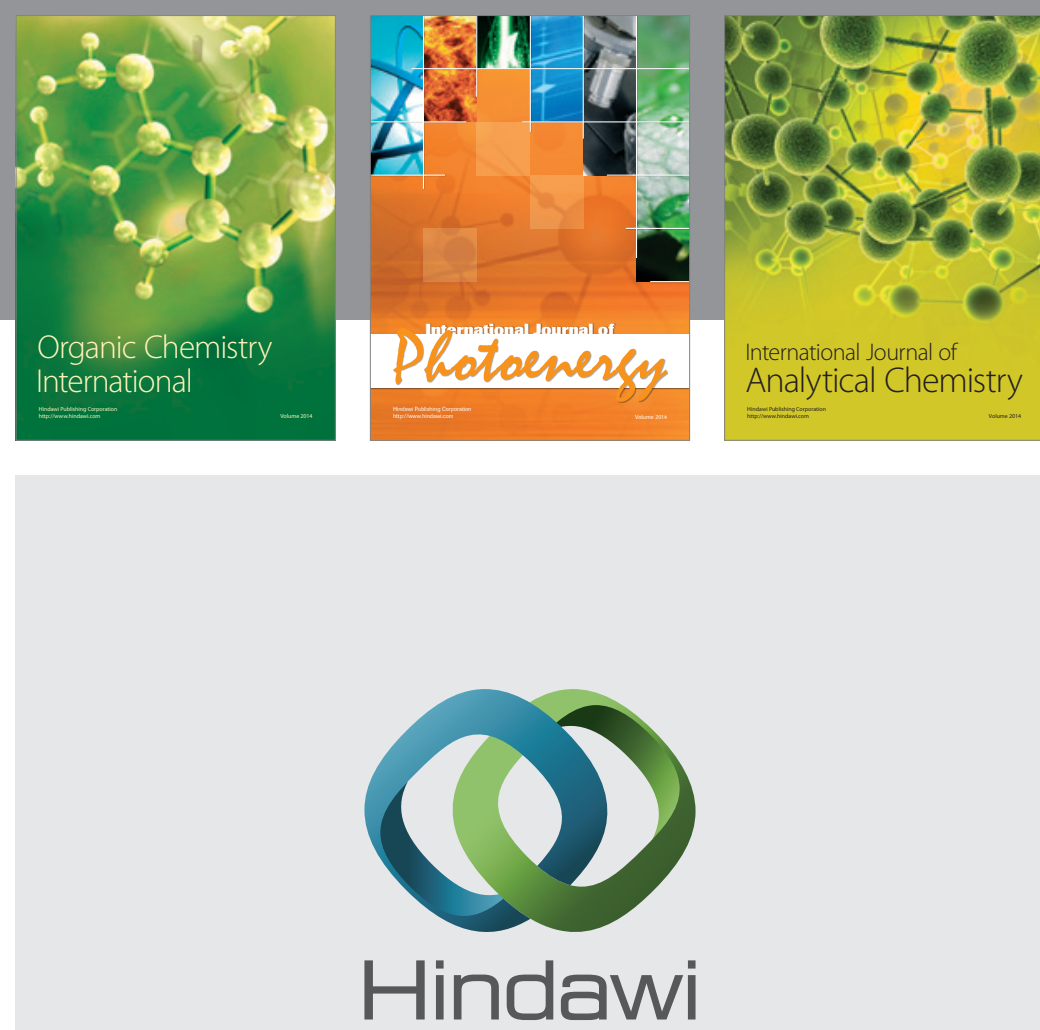

Submit your manuscripts at

http://www.hindawi.com
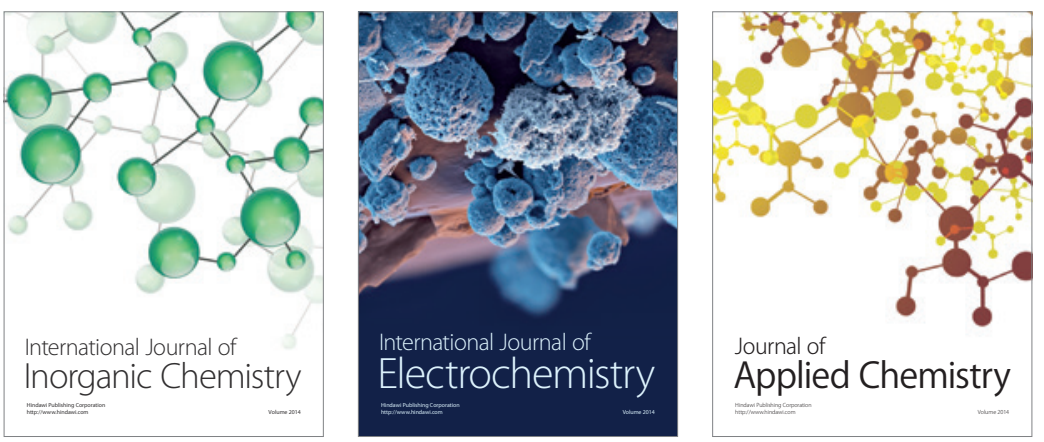

Journal of

Applied Chemistry
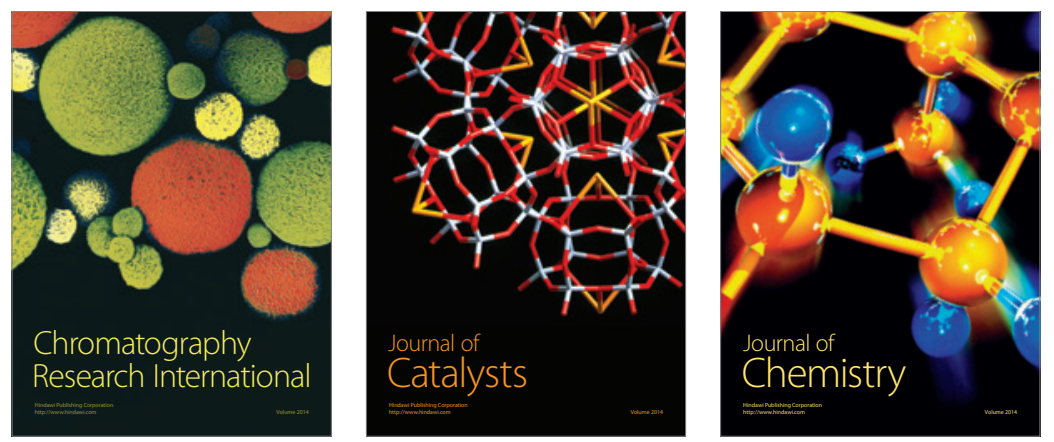
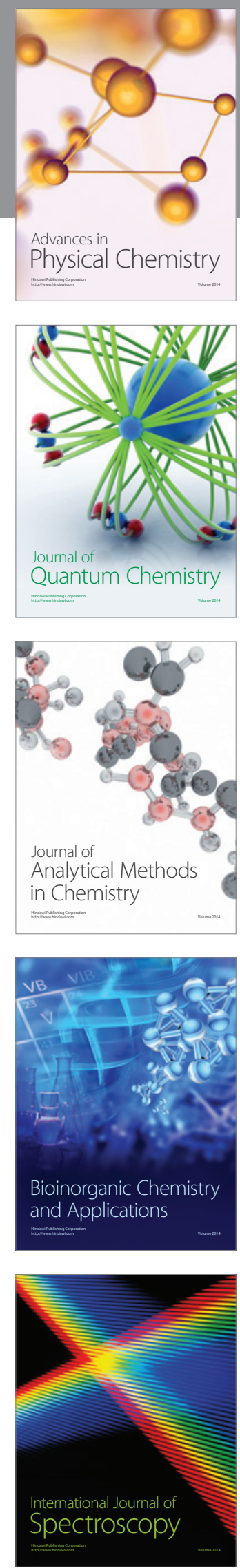